\title{
ASSESSING THE EVOLUTION OF INTERNATIONAL ECONOMIC INTEGRATION USING RANDOM WALK BETWEENNESS CENTRALITY: THE CASES OF EAST ASIA AND LATIN AMERICA
}

\author{
JAVIER REYES \\ Department of Economics, University of Arkansas, USA \\ STEFANO SCHIAVO \\ Department of Economics, University of Trento, Italy \\ OFCE, France \\ GIORGIO FAGIOLO* \\ Sant'Anna School of Advanced Studies, \\ Laboratory of Economics and Management, Italy \\ giorgio.fagiolo@sssup.it
}

Received 7 May 2008

Revised 21 July 2008

\begin{abstract}
Over the past four decades, the high-performing Asian economies (HPAE) have followed a development strategy based on the exposure of their local markets to the presence of foreign competition and on outward-oriented production. In contrast, Latin American (LATAM) economies began taking steps in this direction only in the late 1980s and early 1990s, but before this period they were more focused on the implementation of import substitution policies. These divergent paths have led to sharply different growth performances in the two regions. Yet, standard trade openness indicators fall short of portraying the peculiarity of the Asian experience, and of explaining why other emerging markets with similar characteristics have been less successful over the last 25 years. We offer an alternative perspective on this issue by exploiting recently developed indicators based on weighted network analysis. We study the evolution of the core-periphery structure of the World Trade Network (WTN) and, more specifically, the evolution of the HPAE and LATAM countries within this network. Using random walk betweenness centrality, we show that the HPAE countries are more integrated into the WTN and many of them, which were on the periphery in the 1980s, are now in the core of the network. In contrast, the LATAM economies have at best maintained their position over the 1980-2005 period, and in some cases have fallen in the ranking of centrality.

Keywords: International trade; high-performing Asian economies; Latin American economies; development; growth; networks; complex weighted networks; World Trade Web; centrality.
\end{abstract}

*Corresponding author. Postal address: Sant'Anna School of Advanced Studies, Laboratory of Economics and Management, Piazza Martiri della Libertà 33, I-56127 Pisa, Italy. 


\section{Introduction}

Over the past four decades, two groups of countries have occupied center stage in the discussion of economic development. These two groups have generally been referred to as the high-performing Asian economies (HPAE) and the Latin American (LATAM) countries. Table 1 shows the list of countries that are considered for the analysis presented here. These two regions of the world have been compared from many different perspectives. For instance, some studies focussed on their divergent trends in economic policies regarding openness and import substitution programs over the 1980s. Other contributions stressed their similarities with respect to macroeconomic imbalances and fragile institutional frameworks that led to the financial crises observed in those regions over the late 1990s [44, 25, 4, 10].

Instead of focussing on the specific difference and/or similarities observed between the two regions regarding economic policies, economic growth and stability, here we take these characteristics as given and we center the attention on a different issue, one related to the relationship that exists between economic development and international economic integration. The objective of the current study is to show that the contrasting experiences of economic growth and stability observed in the HPAE and LATAM countries can be associated with different degrees of international economic integration. We use trade flows and a complex network approach to measure network centrality and to assess and characterize the position of the countries of each region within the World Trade Network (WTN). The underlying assumption is that higher degrees of international economic integration are related to more central positions within the WTN, whereas a mere increase in trade openness does not have a similar effect. We are aware that one could use different criteria to define centrality, looking for instance at different products, or at the technological content of trade. Here we just look at aggregated exports and imports. This choice may result in a coarser description of the relevant phenomena, but has the virtue of being consistent with a wide range of trade theories, irrespective of the origin of the gains from trade.

Our results show that the early efforts toward more liberalized markets in HPAE countries, combined with a stable economic environment, have led to substantial differences between these countries and the LATAM economies. And these differences

Table 1. Countries. HPAE - high-performing Asian economies; LATAM — Latin American countries.

\begin{tabular}{ll}
\hline \multicolumn{1}{c}{ HPAE } & LATAM \\
\hline China & Argentina \\
Indonesia & Brazil \\
Korea & Chile \\
Malaysia & Mexico \\
Philippines & Venezuela \\
Thailand & \\
\hline
\end{tabular}


go beyond what economic growth rates and/or stability indicators can show. The HPAE countries are more integrated into the WTN and have moved consistently, over the past 25 years, toward its core, while the LATAM economies have, at best, remained stable in the ranking of centrality.

The rest of the paper is organized as follows. Section 2 offers a brief comparison of HPAE and LATAM countries according to standard macroeconomic statistics. Section 3 discusses data and methodology, and presents the main results. Finally, Sec. 4 presents concluding remarks.

\section{Comparing HPAE and LATAM Regions: Growth, Instability and Openness}

The literature includes several studies that have provided extensive and in-depth discussions regarding the differences and similarities among the HPAE and LATAM regions as far as macroeconomic perspectives are concerned. ${ }^{\mathrm{a}}$ In this section we present a brief comparison based on four macroeconomic indicators that, we believe, provide enough evidence to support the "miracle East Asian economies" and the "Latin American lost decade" arguments [44, 42, 10, 9]. These indicators are wealth, economic growth, inflation, and trade openness.

Strong arguments regarding the different paths of development followed by the two regions can be put forward after a simple examination of the evolution of per capita gross domestic product (GDP), GDP growth rates, inflation rates (as a proxy for stability ${ }^{b}$ ), and total trade-to-GDP ratios (as a proxy for openness) in both regions. Figures 1-4 present the evolution of the averages of these variables for the 1970-2003 period.

It is very clear that the HPAE countries have grown more and faster, have been more stable, and, if the total trade (exports plus imports) to GDP ratio is used to assess trade openness and integration, ${ }^{\mathrm{c}}$ then it is evident that the LATAM average total trade-to-GDP ratio has been - and still is - substantially below that of the HPAE region. Yet, since the liberalization of the late 1980s, LATAM countries have increased their openness, with the share of total trade-to-GDP moving from $25 \%$ in 1990 to $50 \%$ in 2004. However, as will be discussed in the next section, complex network analysis tells us that increased openness has not translated into deeper integration into the WTN.

aSee Refs. 35 and 27 for early comparisons between Latin America and East Asia. More recent studies include Refs. 42, 10 and 26. For specific country/region studies, see Refs. 1, 2, 8, 9, 11, 34, $19,37,40,32,28$ and 43 .

${ }^{\mathrm{b}}$ Reference 15 argues that high rates of inflation are the summary statistics for mismanagement of the economy, at the macroeconomic level, and the inability of governments to implement sound economic policies. This point of view is also implied by Ref. 6 in its study of macroeconomic instability in Latin America.

${ }^{\mathrm{c}}$ References 10 and 9 have used this measure of openness in studies dealing with the HPAE and LATAM regions specifically. 


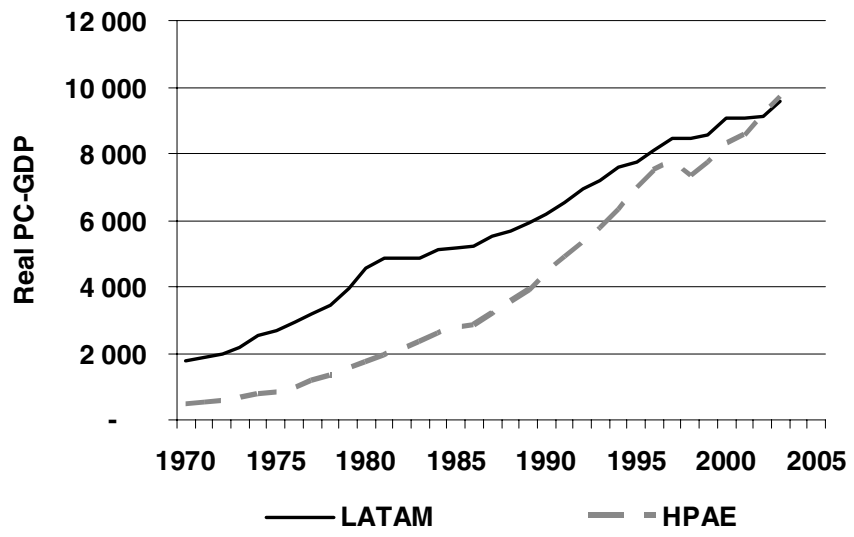

Fig. 1. Real GDP per capita. (Source: Penn World Table 6.2.)

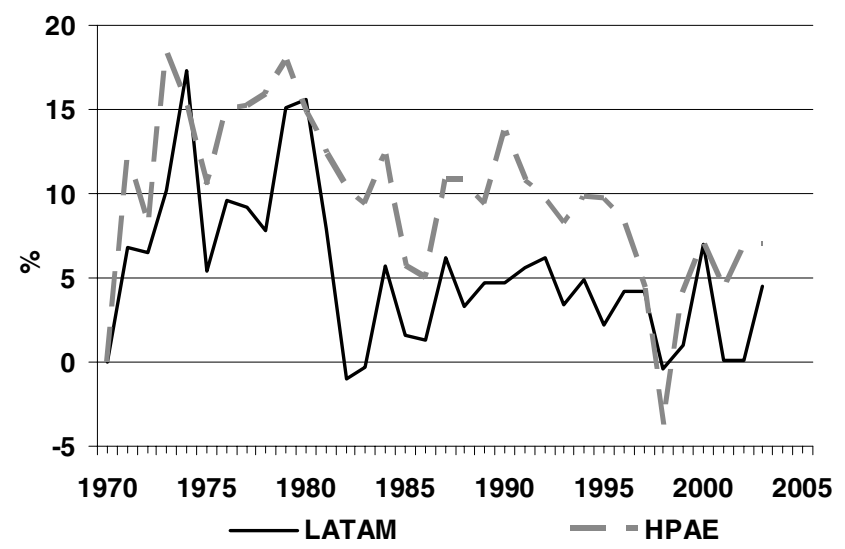

Fig. 2. Real GDP per capita growth rates. (Source: Penn World Table 6.2.)

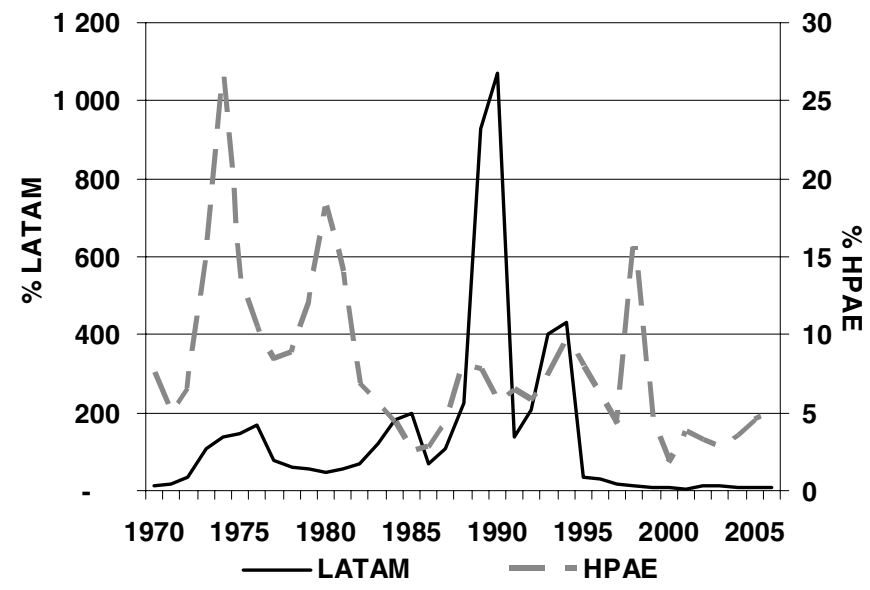

Fig. 3. Inflation rates. (Source: International Financial Statistics (IFS) database, IMF.) 


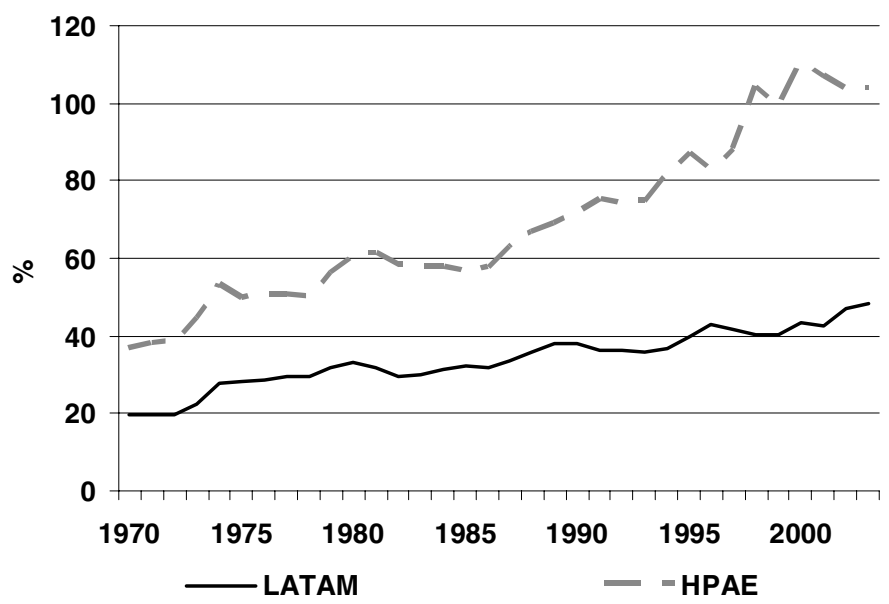

Fig. 4. Total trade-to-GDP ratio. (Source: Penn World Table 6.2.)

\section{Methodology, Data, and Results}

The appeal of using complex network analysis for the study of international economic integration emerges from the fact that it allows the recovery and consideration of the whole structure of the web of trade interactions. Furthermore, by doing so, it allows the exploration of connections, paths, and circuits. When exports and imports to GDP ratios are used to characterize the degree of integration into the world economy of a given country, only first-order trade relationships are captured. Network analysis, on the other hand, accounts for higher-order trade relationships and therefore results in a more in-depth picture of integration. For example, it is possible to assess and fully exploit the length of trade chains, and to characterize the importance of a given country in the network. The study of these properties, as shown by Refs. 23 and 24, can go beyond the description of stylized facts for the overall network and, if used properly, they can be employed to assess the overall degree of international economic integration of the whole network or of a subset of it. References 23 and 24 used a network analysis to derive country-specific network indicators and employed these descriptions for the explanation of macroeconomic dynamics like economic growth and financial contagion. These features of network analysis have been exploited recently in the study of other socioeconomic structures. For example, Refs. 21, 7, 22 and 5 have used network analysis to study, respectively, the interaction among academics through co-authorship, friendship networks based on individuals preferences, networks within the "product space," and credit chains and bankruptcy propagation. ${ }^{\mathrm{d}}$ Previous studies that have looked at the specific characteristics of the WTN include Refs. 39, 29, 38 and, more recently, Refs. 36, $17,18,13$ and 14 . The findings reported in these studies suggest that the WTN is 
very symmetric, it has a core-periphery structure, there is evidence of a "rich club phenomenon" where countries that have higher trade intensities trade a lot among themselves and, surprisingly, that the overall network structure is fairly stationary through time. The current paper follows closely Refs. 23 and 24, to the extent that it uses network indicators to assess the degree of integration of a set of countries, and then exploits this methodology to draw conclusions regarding the different degrees of integration observed for the HPAE and LATAM economies.

The data used to carry out the study are extracted from the COMTRADE database. Bilateral trade data for 171 countries over the 1980-2005 period are used to build the trade matrix for the countries considered (more on that in the appendix). In the resulting matrix, columns represent importing countries, while rows denote exporting countries. This matrix is used to build adjacency $(A)$ and weighted $(W)$ matrices needed for the computation of network indicators. The adjacency matrix simply reports the presence of a trade relationship between any two countries; therefore we set the generic entry for the matrix as $a_{i j}^{t}=1$ if and only if exports of country $i$ to country $j$ (defined as $e_{i j}^{t}$ ) are strictly positive in year $t$. As to the weighted matrix $(W)$, Refs. 13 and 14 have shown that the majority of network indicators for the WTN are robust to different weighting procedures. For example, one can use the actual trade flow as the weight for each link, $w_{i j}^{t}=e_{i j}^{t}$, or a weighted trade measure like exports as a proportion of GDP, i.e. $w_{i j}^{t}=e_{i j}^{t} / \mathrm{GDP}_{i}^{t}$. In this study we use actual trade flows (i.e. levels) for the benchmark analysis and we provide some discussion, for robustness purposes, of alternative weighting schemes later in the paper.

It should be noted that the WTN is, by nature, a weighted (valued links) and directed network (exports and imports). Following Refs. 13 and 14 the analysis employs a weighted and undirected (WUN) approach since the WTN turns out to be sufficiently symmetric. ${ }^{\text {e }}$ For this WUN analysis each entry of the original weighted matrix $(W), w_{i j}^{t}=e_{i j}^{t}$, is replaced by $w_{i j}^{t *}=\frac{1}{2}\left(e_{i j}^{t}+e_{j i}^{t}\right)$.

\subsection{Random walk betweenness centrality}

In this paper, we proxy country integration (centrality) in the WTN by means of random walk betweenness centrality (RWBC). Following Refs. 31 and 16, consider a generic node $i$ for which we want to compute the RWBC and an impulse generated from a different node $h$, which works its way through the network in order to get to target node $k$. Let $f(h, k)$ be the source vector $(N \times 1)$, such that $f_{i}(h, k)=1$ if $i=h, f_{i}(h, k)=-1$ if $i=k$, and 0 otherwise. Reference 31 shows that Kirchoff's law of current conservation implies that

$$
v(h, k)=[D-W]^{-1} f(h, k),
$$

e The results for the symmetry index, as computed in Ref. 12, range between 0.006 (lowest) and 0.013 (highest) for the period 1980-2005. The symmetry index ranges from 0 to 1 , where zero denotes full symmetry and 1 represents maximum asymmetry. 
where $v(h, k)$ denotes the $N \times 1$ vector of node voltages, $D=\operatorname{diag}(s)$, where $s$ is the node-strength vector, and $[D-W]^{-1}$ is computed using the Moore-Penrose pseudoinverse. This implies that the intensity of the interaction flowing through node $i$ originated from node $h$ and getting to target node $k$, is determined by

$$
I_{i}(h, k)=W \cdot\left|v(h, k)-\mathbf{1} v_{i}(h, k)\right|,
$$

where $I_{h}(h, k)=I_{k}(h, k)=1$ and $\mathbf{1}$ is the conformable unit vector. Therefore the RWBC for node $i$ can be computed as

$$
\mathrm{RWBC}_{i}=\frac{\sum_{h} \sum_{k \neq h} I_{i}(h, k)}{N(N-1)} .
$$

RWBC is a measure of node centrality that captures the effects of the magnitude of the relationships that a node has with other nodes within the network as well as the degree/strength of the node in question. Reference 31 offers an intuitive explanation for RWBC. It assumes that a source node sends a message to a target node. The message is initially transmitted to a neighboring node and then it follows an outgoing link from that vertex, chosen randomly, and continues in a similar fashion until it reaches the target node. In the original measure presented in Ref. 31, the probabilities assigned to outgoing edges are all equal, but in Ref. 16 these probabilities are determined by the magnitude of the outgoing trading relationships. Hence links that represent greater magnitude for a trading relationship will be chosen with higher probability. In other words, RWBC exploits (randomly) the whole length of the trade chains present in the network for country $i$ and, therefore, is a good measure for the degree of integration that a given node has within the WTN.

It should be noted that the RWBC of a given node is only partially determined by its volume of trade. Indeed, any two countries characterized by the same level of total trade (or even the same trade-to-GDP ratio) can have very different levels of RWBC and therefore different degrees of international economic integration (as defined in this study). The reason for this is that the RWBC of a given node depends on how much its partners trade, and on how many partners they trade with, how much the partners of their partners trade and how many partners they trade with, and so on. The fact that RWBC considers the whole length of trade chains is the main reason why it provides a much more detailed characterization of integration into the WTN.

Furthermore, RWBC is a measure that allows the characterization of the coreperiphery structure of the WTN and also permits the identification of the countries in the core and the periphery. Using a percent-rank analysis, the network may be divided into core countries $(\mathrm{C})$, inner-periphery countries (I-P), secondaryperiphery countries ( $\mathrm{S}-\mathrm{P})$, and outside-of-the-periphery countries $(\mathrm{O})$. A country is classified here as a $\mathrm{C}$, I-P, S-P, or $\mathrm{O}$ according to where it lies within the RWBC distribution for the overall network (171 countries). A country is classified as a $\mathrm{C}$ country if its RWBC is above the 95th percentile, I-P if it is above the 90th but 
below the 95 th percentile, $\mathrm{S}-\mathrm{P}$ if it is above the 85 th but below the 90 th percentile, and $\mathrm{O}$ otherwise. ${ }^{\mathrm{f}}$ The results for the HPAE and LATAM regions, as well as the results for India and the average for the G7 countries, are presented and discussed here. The reason to include the G7 and India, a recent globalizer, is for comparison. Indeed, HPAE countries have attained a high level of integration within the WTN and it is interesting to analyze their position with respect to other countries.

Table 2 presents the evolution using the core-periphery classification, while averages of the RWBC distribution over time for India, the G7, the HPAE, and the LATAM countries are presented in Fig. 5. The clear message that emerges is that the gap, according to RWBC, between the G7, the HPAE countries (with and without China), and India has been closing while that between all these regions and the LATAM economies has remained. It should be noted that when analyzed independently, one country that clearly diverges from the path of the LATAM region is Brazil. The results for this country (Table 2) show that it is clearly among the top countries according to RWBC but it is also true that its initial value in 1980 was already high. RWBC levels for Argentina, Chile, and Mexico have remained constant. Yet, the result for Venezuela shows that this country is moving away from the core of the WTN. All of the LATAM countries except Brazil are currently at or below the 80th percentile of the distribution, while countries like China and Korea are above the 95th percentile and can be considered as part of the core of the network along with the G7 countries. The only HPAE country that is outside the 80th percentile is the Philippines, and to some extent it can be argued that its degree of integration has stalled. It should be noted that the argument regarding the integration of India into the WTN seems to be well founded. This country has moved up in the RWBC rankings, consistently.

\subsection{Robustness checks}

As mentioned before, the weighted approach followed in the current study can be carried out using different weighting procedures. In the previous sections, the RWBC measure was computed by using the actual trade flows as the weights for the links between the countries considered in the study.

An alternative, meaningful weighting procedure is to employ trade flows divided by GDP. Table 3 and Fig. 6 report the results for this procedure. The conclusions regarding the increased level of centrality for the HPAE countries and the stagnant position of the LATAM region still hold, even though there are some differences for individual cases.

The robustness of the results across weighting procedures matches the findings reported in Refs. 13 and 14. These used international trade data provided by Ref. 20 for the $1981-2000$ period and included 159 countries. Their findings

\footnotetext{
${ }^{\mathrm{f}}$ Results do not dramatically change if the relative criterion considered here is substituted by an absolute criterion - where core status is attributed to countries with centrality results above the sample mean plus one standard deviation.
} 


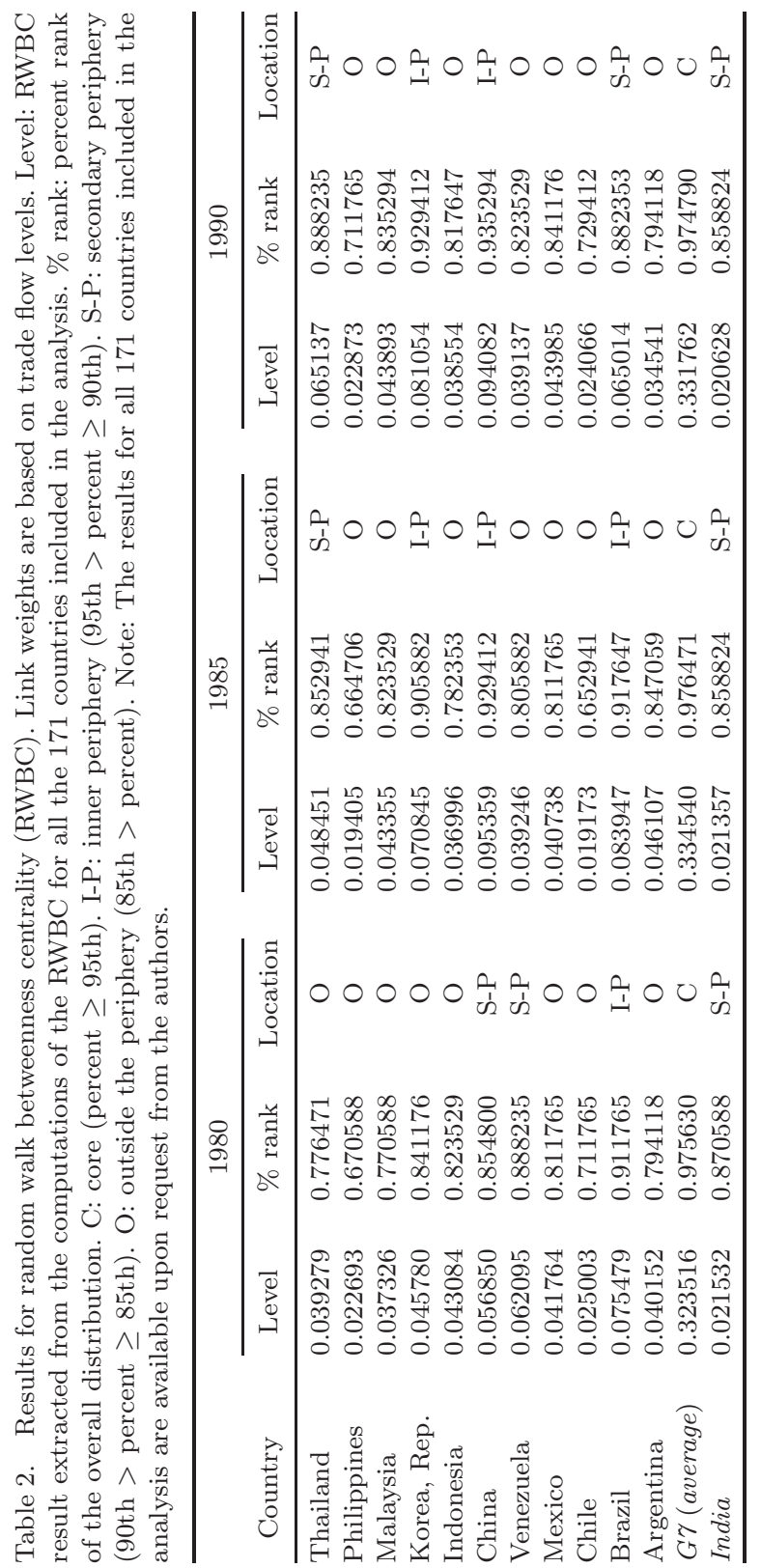




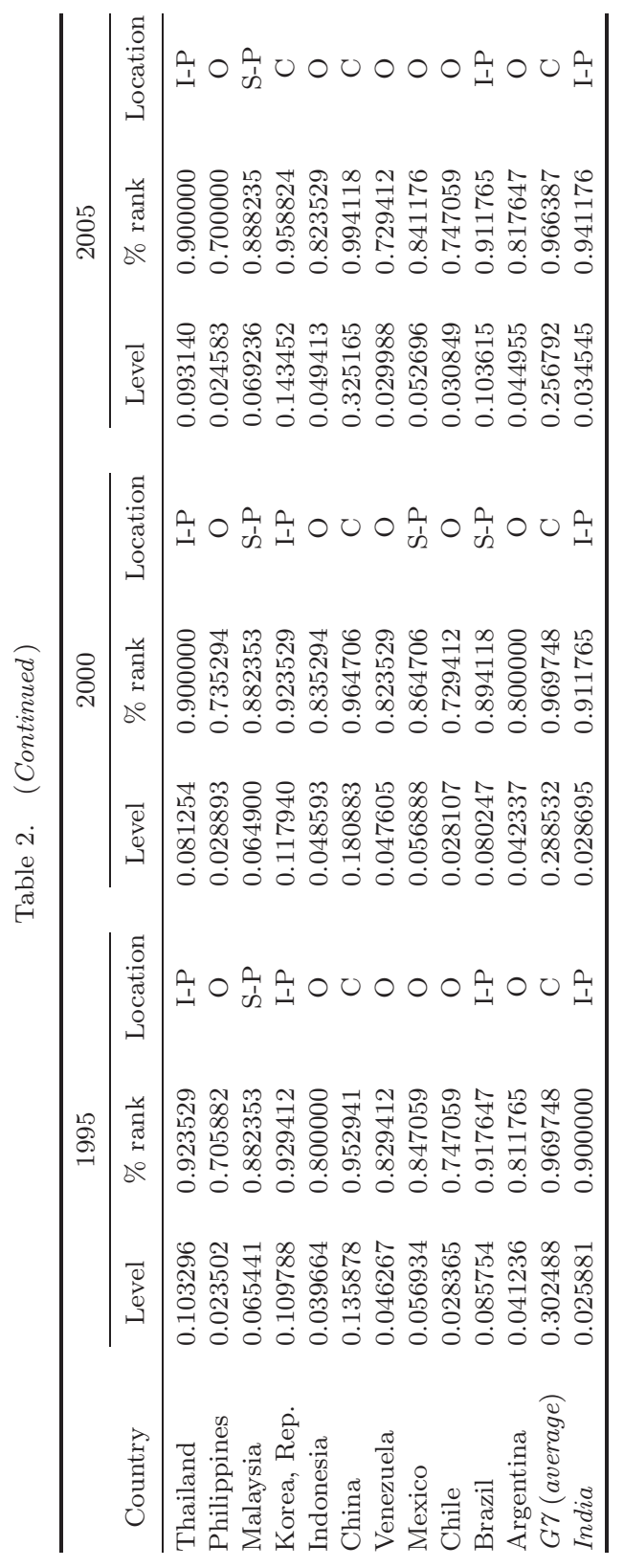




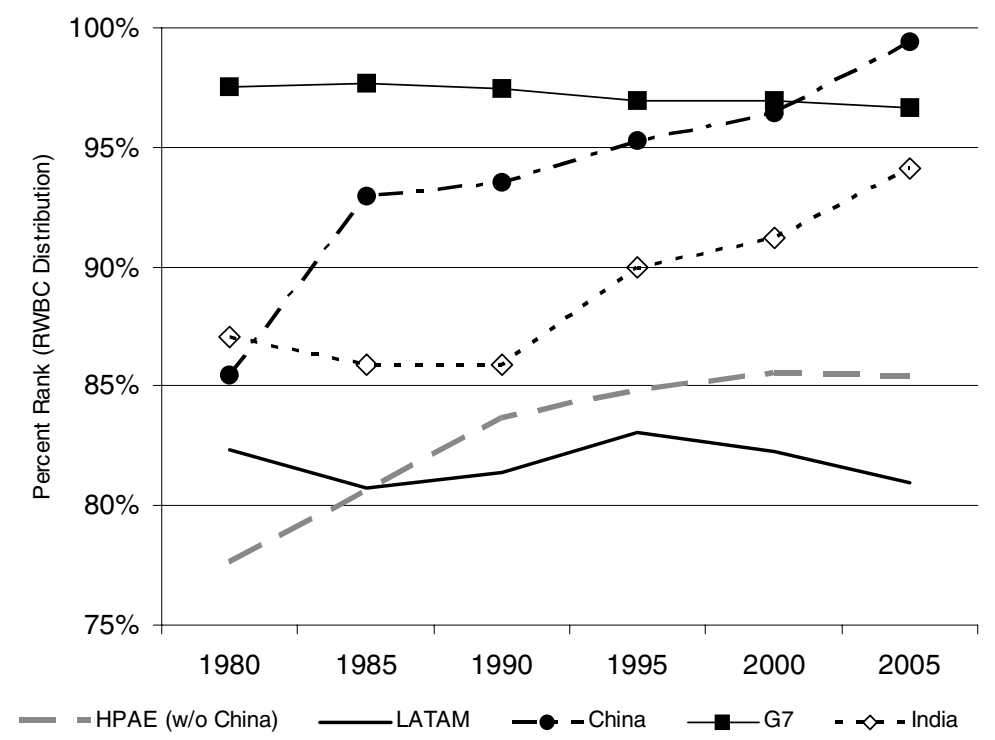

Fig. 5. Average random walk betweenness centrality (RWBC). Link weights are based on trade flow levels.

regarding the constitution of the core of the network match those reported here, since they showed that China and South Korea were part of the core of the WTN in the year 2000. As a final robustness check, Refs. 13 and 14 report a surprising stationarity for the characteristics of the overall network. The population averages for the RWBC, throughout the sample period, are around $0.036-0.038$ for the case that uses the trade flows as the weights for the links between countries and 0.045-0.048 for the case that uses the total trade-to-GDP ratios. The stability of these averages confirms that the stationarity of the characteristics of the WTN is also present in our study. That is to say, the overall network distribution does not change much through time, but the composition of the core and of the periphery do change.

The foregoing results show that from our RWBC analysis one is able to draw interesting implications as far as the dynamics of trade patterns is concerned. A further question naturally arising concerns the extent to which the percent-rank study of the RWBC distributions really adds new insights as compared to traditional international trade statistics. To address this issue, we have replicated our percent-rank exercise when RWBC is simply replaced by standard total trade-to-GDP ratios. As shown in Fig. 7, results are quite different and overall do not allow us to draw the same implications that we derived from Figs. 5 and 6 and RWBC percent-rank analysis. Note indeed that all the countries (and groups thereof) under analysis occupy lower percent-rank positions. Furthermore, HPAE countries are closer than LATAM countries to G7 ones, but do not seem to rapidly catch up. Indeed, the gap between HPAE and LATAM countries seems rather constant but rather smaller 


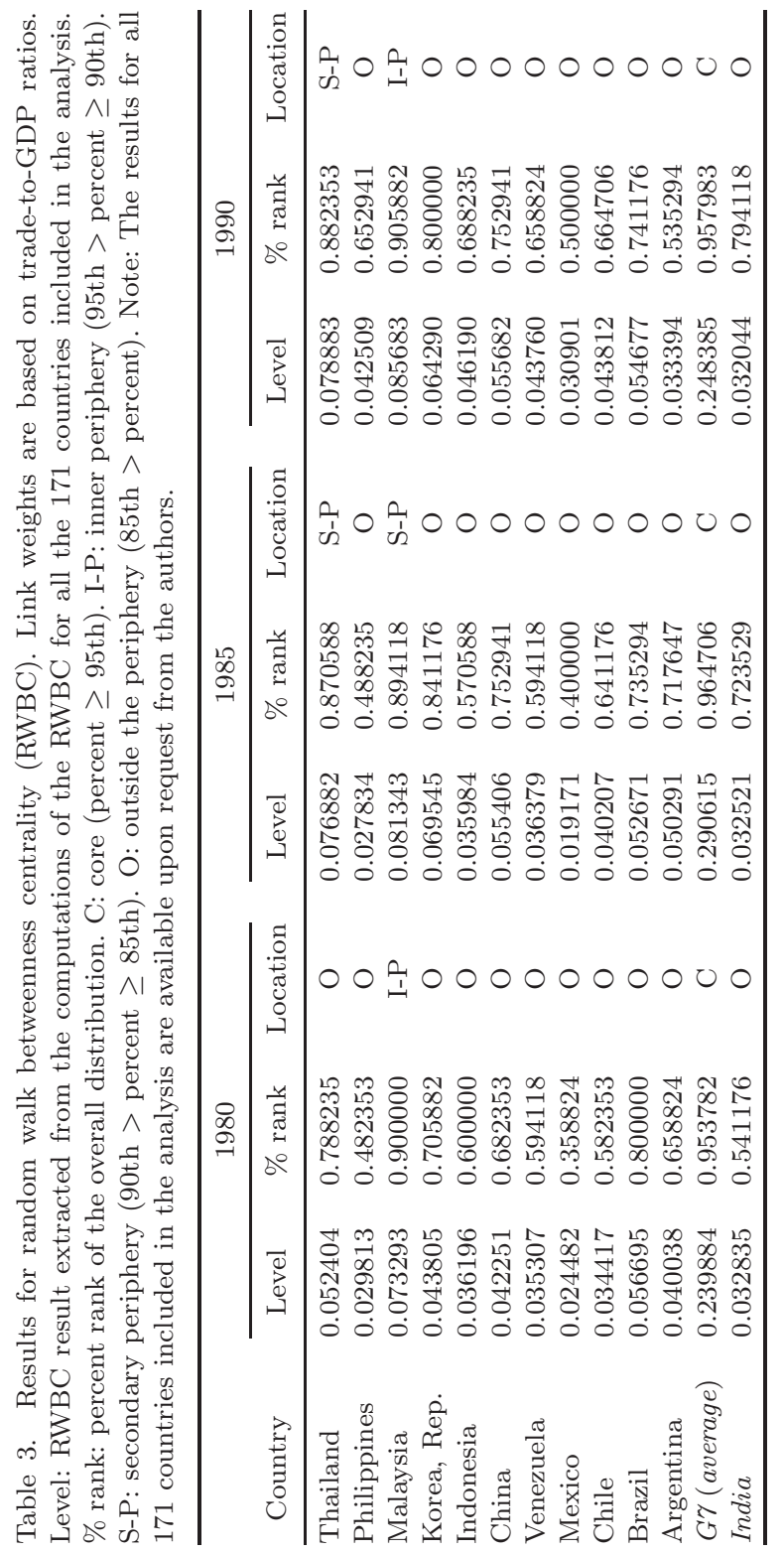




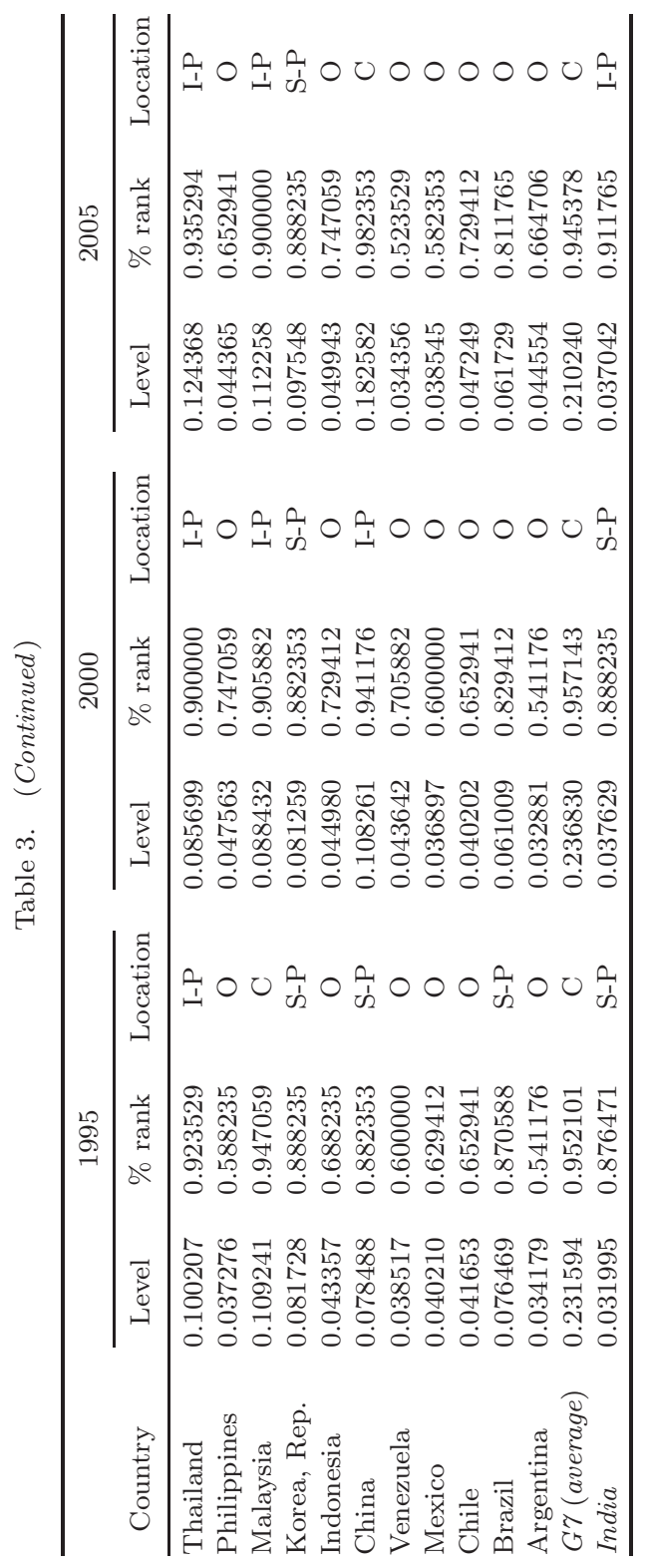




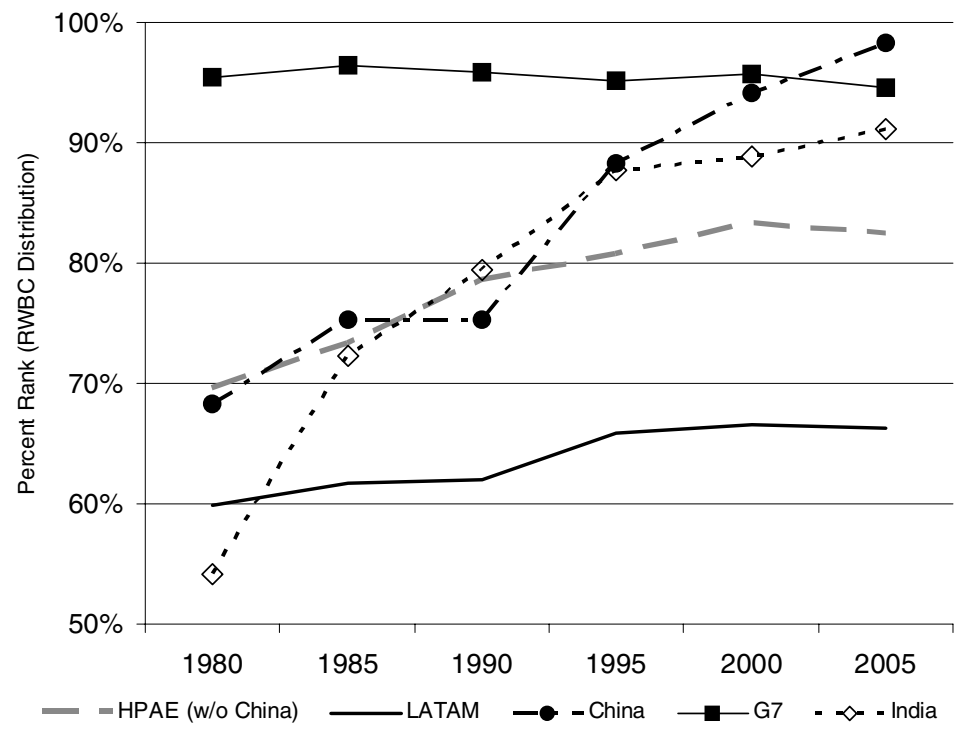

Fig. 6. Average random walk betweenness centrality (RWBC). Link weights are based on tradeto-GDP ratios.

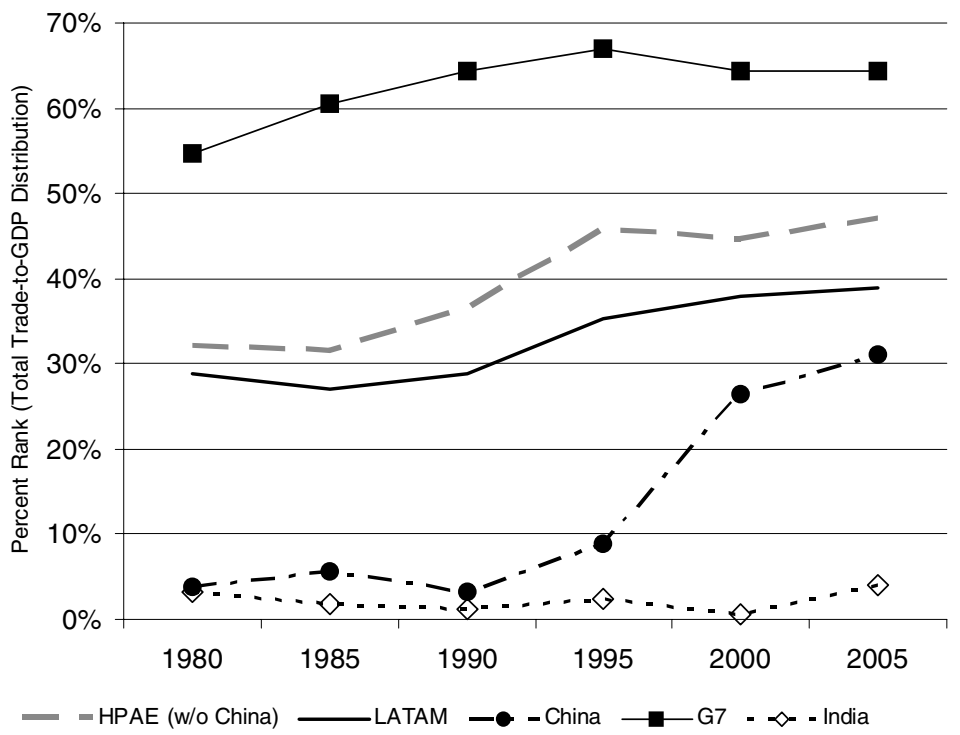

Fig. 7. Average total trade-to-GDP ratios.

than in the RWBC case. India occupies very low positions, whereas China scores below LATAM countries, although it is rapidly climbing. Overall, it appears that RWBC can provide a sharper and more meaningful picture than trade-to-GDP ratios as far as economic integration is concerned. 


\section{Concluding Remarks}

The objective of this paper is to assess whether the observed high economic growth rates and stability of the HPAE region, compared to the LATAM region, could be associated with different (higher) degrees of international economic integration. To answer this question the paper goes beyond the standard analysis of total trade (exports plus imports) to GDP ratios and argues that complex network analysis provides a better understanding of integration. It proposes proxying the degree of international economic integration of a given country by analyzing the position of this country within the WTN in terms of RWBC.

The increasing total trade-to-GDP ratios, observed throughout the past 25 years, would point in the direction of a higher degree of economic integration for both regions, more so for the HPAE region but still substantially increasing for both. The averages for the total trade-to-GDP ratio for these regions went from 20-25\% for both regions in 1980 to around $50 \%$ and $80 \%$ for LATAM countries and HPAE economies, respectively. Contrary to these conclusions, using the RWBC measure, the paper exploits the characteristics of the WTN and shows that there are clear differences in the levels and patterns of international economic integration between the two regions. The pattern that emerges shows a steady increase in the degree of integration for the HPAE region, a result that is consistent with the increase in the total trade-to-GDP ratio. Conversely, the degree of integration of LATAM economies, according to RWBC, has remained constant, contrary to what is suggested by the mere observation of an increase in the ratio of total trade to GDP.

The increased presence of the HPAE region in the WTN has policy implications that concern international institutions like the World Trade Organization. This rise in economic integration, due to the number and intensity of trading relationships, enhances the "presence" of the HPAE economies and this could lead to pressure for changes regarding international trade policies and negotiations in current and future trade negotiations rounds. Given that the results are sensible and point toward interesting patterns, otherwise not identified through standard trade openness measures, we believe that network analysis may suggest a new and, presumably, very fruitful route for the analysis of trade flows that go beyond aggregate flows. In this direction, an interesting extension to the present study would be to characterize the evolution of trade networks at the industry level. The analysis of disaggregated industry-level data might in fact clarify whether the effects of integration on growth are the result of the specific types of goods in which a given region (or even country) specializes.

\section{Appendix A. Data}

The bilateral trade data are extracted from the COMTRADE database housed at the United Nations. The database contains more than 200 countries as reporters 
and more than 250 as partners. After the elimination of regional and income aggregations, and other classifications (free trade zones, neutral zones, and unspecified origin), the database has been reduced to participating countries in the WTN for the period of 1980-2005. Before one performs the analysis, a decision has to be made with respect to countries that stop existing or begin existing after the breakup of a given original country (such as the USSR or Yugoslavia), or because these countries reported their trade flows as ones for some of the periods considered (this is the case for Belgium and Luxembourg). In this paper, for simplicity, the following groups are considered as one node (reporter and partner):

- Belgium-Luxembourg: Belgium and Luxembourg

- Czechoslovakia: Czech Republic and Slovak Republic

- Eritrea-Ethiopia: Eritrea and Ethiopia

- Yugoslavia, FR: Croatia, Macedonia, Yugoslavia, Slovenia, Serbia/Montenegro

- Russia: Armenia, Azerbaijan, Belarus, Estonia, Georgia, Kazakhstan, Kyrgyz Republic, Lithuania, Latvia, Moldova, Russian Federation, Tajikistan, Turkmenistan, Ukraine, Soviet Union, and Uzbekistan

The aggregation of these nodes into one, for every column, has been simply done to avoid a sudden change in the number of nodes in the network that could have resulted in structural network changes even though the trade flows did not change so dramatically. An alternative would be to drop these countries from the analysis, and consider only countries that existed throughout the whole period of 1980-2005, but we believe that this could lead to a greater loss of information than the one that could result from the aggregation. In the end, the trade data for the study include 171 countries for the 1980-2005 period. Given the stationarity of the network properties, reported in previous studies and confirmed here, we perform only the analysis for 1980, 1985, 1990, 1995, 2000, 2004, and 2005.

The data for GDP per capita and the trade shares as a percentage of GDP are extracted from Penn World Table 6.2, while the data for inflation are computed from consumer price indices extracted from the International Financial Statistics (IFS) database, housed at the International Monetary Fund.

\section{References}

[1] Amsden, A., Asia's Next Giant: South Korea and Late Industrialization (Oxford University Press, 1989).

[2] Amsden, A., Why isn't the whole world experimenting with the East Asian model to develop? Review of the East Asian miracle, World Devel. 22 (1994) 627-633.

[3] Barabási, A., Statistical mechanics of complex networks, Rev. Mod. Phys. 74 (2002) 47-97.

[4] Barro, R., Economic growth in East Asia before and after the financial crisis. Working Paper 8330, NBER (2001).

[5] Battiston, S., Gatti, D., Greenwald, B. and Stiglitz, J., Credit chains and bankruptcy propagation in production networks, J. Econ. Dynam. Control 31 (2007) 2061-2084. 
[6] Corbo, V. and Rojas, P., Investment, macroeconomic instability and growth: The Latin American experience, Revista de Analisis Economico 8 (1993) 19-35.

[7] Currarini, S., Jackson, M. and Pin, P., An economic model of friendship: Homophily, minorities and segregation, Research paper, Department of Economics, University Ca' Foscari of Venice (2007).

[8] de Gregorio, J., Economic growth in Latin America, J. Devel. Econ. 39 (1992) 59-84.

[9] de Gregorio, J., Economic growth in Latin America: From the disappointment of the twentieth century to the challenge of the twenty-first. Working Paper 377, Central Bank of Chile (2006).

[10] de Gregorio, J. and Lee, J.-W., Growth and adjustment in East Asia and Latin America, Economia 5 (2004) 69-134.

[11] Edwards, S., Crisis and Reform in Latin America: From Despair to Hope (Oxford University Press, 1995).

[12] Fagiolo, G., Directed or Undirected? A new index to check for directionality of relations in socio-economic networks, Econ. Bull. 3 (2006) 1-12.

[13] Fagiolo, G., Reyes, J. and Schiavo, S., The evolution of the World Trade Web: A weighted-network analysis. Lem Working Paper Series, 2007-17 (2007). Available at: http://www.lem.sssup.it/wplem/files/2007-17.pdf

[14] Fagiolo, G., Schiavo, S. and Reyes, J., On the topological properties of the World Trade Web: A weighted network analysis, Physica A 387 (2008) 3868-3873.

[15] Fischer, S., The role of macroeconomic factors in growth, J. Monet. Econ. 32 (1993) 485-512.

[16] Fisher, E. and Vega-Redondo, F., The linchpins of a modern economy. Working Paper, California Polytechnic (2006).

[17] Garlaschelli, D. and Loffredo, M., Fitness-dependent topological properties of the World Trade Web, Physic. Rev. Lett. 93 (2004) 188701.

[18] Garlaschelli, D. and Loffredo, M., Structure and evolution of the world trade network, Physica A 355 (2005) 138-144.

[19] Gavin, M. and Perotti, R., Fiscal policy in Latin America, NBER Macroecon. Annu. 12 (1997) 11-61.

[20] Gleditsch, K., Expanded trade and GDP data, J. Conflict Resolution 46 (2002) 712 724. Available at http://ibs.colorado.edu/ksg/trade.

[21] Goyal, S., Moraga, J. L. and van der Leij, M., Economics: Emerging small world, J. Pol. Economy 114 (2006) 403-412.

[22] Hidalgo, C., Klinger, A., Barabási, B. and Hausmann, R., The product space conditions and the development of nations, Science 317 (2007) 482-487.

[23] Kali, R. and Reyes, J., The architecture of globalization: A network approach to international economic integration, J. Int. Bus. Stud. 38 (2007a) 595-620.

[24] Kali, R. and Reyes, J., Financial contagion on the International Trade Network. University of Arkansas, 2007b.

[25] Kaminsky, G. and Reinhart, C., Financial crises in Asia and Latin America: Then and now, Am. Econ. Rev. 88 (1998) 444-449.

[26] Krasilshchikov, V., The East Asian "tigers": Following Russia and Latin America?, Working Papers - Programa Asia \& Pacifico 17, Centro Argentino de Estudios Internacionales (2006).

[27] Lin, C.-Y., Latin America vs. East Asia: A Comparative Development Perspective (M.E. Sharpe, New York, 1989).

[28] Lora, E. and Panizza, U., Structural reforms in Latin America under scrutiny. Research Department Working Paper 470, IADB (2002). 
[29] Nemeth, R. and Smith, D., International trade and world-system structure: A multiple network analysis, Review: A Journal of the Fernand Braudel Center 8 (1985) $517-560$.

[30] Newman, M., The structure and function of complex networks, SIAM Rev. 45 (2003) $167-256$.

[31] Newman, M., A measure of betweenness centrality based on random walks, Soc. Networks 27 (2005) 39-54.

[32] Park, Y. C. and Lee, J.-W., Recovery and sustainability in East Asia, in Managing Currency Crises in Emerging Markets, eds. Dooley, M. and Frankel, J. (Chicago University Press, 2002), pp. 275-320.

[33] Pastos-Satorras, R. and Vespignani, A., Evolution and Structure of the Internet (Cambridge University Press, 2004).

[34] Rodrick, D., Getting intervention right: How South Korea and Taiwan grew Rich, Econ. Policy 20 (1995) 55-107.

[35] Sachs, J., External debt and macroeconomic performance in Latin America and East Asia, Brookings Papers on Economic Activity 2 (1985) 523-573.

[36] Serrano, A. and Boguñá, M., Topology of the World Trade Web, Phys. Rev. E 68 (2003) 015101R.

[37] Singh, A., Savings, investment and the corporation in the East Asian miracle, J. Dev. Stud. 34 (1998) 112-137.

[38] Smith, D. and White, D., Structure and dynamics of the global economy: Network analysis of international trade, 1965-1980, Soc. Forces 70 (1992) 857-893.

[39] Snyder, D. and Kick, E., Structural position in the world system and economic growth 1955-1970: A multiple network analysis of transnational interactions, Am. J. Sociol. 84 (1979) 1096-1126.

[40] Stiglitz, J., From miracle to crisis to recovery: Lessons from four decades of East Asian experience, in Rethinking the East Asian Miracle, eds. Stiglitz, J. and Yusuf, S. (Oxford University Press, 2001), pp. 509-525.

[41] Watts, D. and Strogatz, S., Collective dynamics of "small-world" networks, Nature 393 (1998) 440-442.

[42] Weeks, J., Latin America and the "High Performing Asian Economies": Growth and debt, J. Int. Deve. 12 (2000) 625-654.

[43] Weiss, J. and Jalilian, H., Industrialization in an age of globalization: Some comparisons between East and South Asia and Latin America, Oxford Devel. Stud. 32 (2004) 283-307.

[44] World Bank, The East Asian Miracle: Economic Growth and Public Policy (Oxford University Press, 1993). 